\title{
MORTALIDADE POR DIABETES MELITO NO MUNICÍPIO DE SÃO PAULO*
}

\author{
DONALD WILSON **:
}

I NTRODUCÃO

Há, em todo o mundo, grande aumento da mortalidade por doenças não transmissiveis, ao passo que diminui aquela por doenças transmissiveis. Tivemos, já, ocasião de demonstrar êsse aumento no Munićpípio de São Paulo, em trabalho anterior :".

Dentre as doenças não-transmissíveis, o diabetes melito, embora não apresente um destaque como o câncer e as doenças do coração, registra um aumento progressivo na sua mortalidade e, de 55: causa de cibito em 1900, com um coeficiente de mortalidarle proporcional de 1),07', passou a sel' a 10" causa em 1960, com um coeficiente de mortalidade proporcional de $2,11^{\prime} ; "$ ".

Inúmeros fatôres, teòricamente, influem para que a mortalidarle por diabetes melito aumente, fatôres êsses que influem, também, na morbirlarle. Vêstes, os mais importantes são os seguintes:

1) Anmento du vidu médice - Sendo o diabetes melito uma doenca cute se manifesta, na maioria dos casos, por volta ros 50 anos ", é rle se esperar que, aumentando a vida média, aumente o número de indivíduos que apresentam diabetes melito, o que acarreta uma mortalidade maior. No Município de São Paulo, a vida média, no triênio 1949 a 1951, era de 54,98 anos para o sexo masculino e de 60,21 para o sexc feminino. Em 19:8 era de 59,86 anos para o sexo masculino e 66,11 para of feminino'.

2) Molhor diugnóstico - Esste fator, incontestàvelmente, contribuiu para o aumento da mortalidade por diabetes melito, não só através do aperfoiçoamento das técnicas de laboratório, mas também atra-

Recebido para puhlicação em 4-3-1962.

Trabalho da Cadeila de Técnica de Saúde Pública I Prof. Rodolfo dos Santos Mascarenhass da Faculdade de Higiene e Saúde Pública da Universidade de Sào Paulo.

Assistente do Merlicina Preventiva da Faculdade de Medicina da Universidace dò S.ào Paulo. 
vés da generalização do conceito de diabetes oculto, levando a exames de rotina, e, em menor escala, o fato de a população melhor conhecer, atualmente, a doença e procurar o médico com maior freçüencia.

3) Melhor tiatumento - Com a melhora das técnicas terapêticas, especialmente a introdução da insulina no arsenal terapêtico, seu posterior aperfeiçoamento (insulinas de depósito) e o aparecimento do: agentes hipoglicemiantes orais (tolbutamina, clorpropamida, etc.), tornou-se possível oferecer, aos diabéticos, meios para maior sobrevida, além de aumentar a fertilidade de mulheres diabéticas — aumentando a fertilidade pròpriamente dita es o período de fertilidade " - o que leva a um acúmulo de diabéticos, ano a ano, tomanclo o gen diabetogênico mais comum na população, o que vem facilitar o aparecimento de homozigotos recessivos. Êstes fatos levam a um aumento da morbidade $t$, conseqüentemente, a um aumento da mortalidade.

1) Diminuiçüo da mortalidade das doenças transmissiuers - A grande conquista no campo dos quimioterápicos permitiu reduzir grandemente a mortalidade das doenças transmissiveis, permitindo a sobrevivência de diabéticos e diabéticos potenciais, aumentando a mortalidalidarle através do aumento da morbidade.

As revisões na classificação internacional de doenças e causas de óbito que, indubitàvelmente, influíram na mortalidade por outras doenças, como o câncer, por exemplo, pouco influíram na mortalidarle por diabetes melito, pois esta doença, em tôdas as revisões, encontra-se individualizada.

Já há, em nosso meio, quem julgue ser o diabetes meìito um problema de saúde pública. Em trabalho anterior" pudemos demonstrar que sem pesquisa não poderemos concluir se a doença é ou não problema de tal ordem.Êste trabalho pretende ser uma contribuição para tal pesquisa, analisando os dados de mortalidade tão extensa e profundamente quanto os mesmos nos permitam.

\section{MORTALIDADE PROPORCIONAL NO PFRIODO 1900 A 1960}

A mortalidade proporcional do diabetes melito vem aumentando progressivamente desde 1900 até 1960 (tabela 1 e gráfico 1).

Naturalmente, êsse crescimento se faz de maneira irregular, tornando-se mais intenso à medida que o tempo passa, lembrando, a curra, uma parábola. Aplicamos a equação da parábola $\left(y-u+b x+c x^{*}\right)$ aos nossos dados e verifificamos que esta se ajusta muito bem (gráf. 1). 
Tabela 1 - Mortalidade proporcional do diabetes melito no Município de São Paulo no período de 1900 a 1960.

\begin{tabular}{|c|c|c|c|c|}
\hline & \multirow{2}{*}{ Ano } & \multicolumn{2}{|c|}{ obitos } & \multirow{2}{*}{$\begin{array}{c}\text { Coeficientes de mor- } \\
\text { talidade proporcional } \\
(\%)\end{array}$} \\
\hline & & Diabetes melito & Tôdas as causas & \\
\hline 1900 & $\ldots \ldots \ldots \ldots$ & 3 & 4.108 & 0,07 \\
\hline 01 & $\cdots$ & 2 & 4.514 & 0,04 \\
\hline 02 & $\ldots \ldots \ldots \ldots$ & 4 & 5.199 & 0,08 \\
\hline 03 & $\cdots$ & 5 & 4.604 & 0,11 \\
\hline 04 & & 6 & 4.922 & 0,12 \\
\hline 05 & $\ldots \ldots$ & 4 & 4.852 & 0,08 \\
\hline 06 & $\ldots \ldots \ldots \ldots$ & 2 & 5.406 & 0,04 \\
\hline 07 & $\cdots$ & 9 & 5.129 & 0,18 \\
\hline 08 & $\cdots$ & 6 & 5.760 & 0,10 \\
\hline 09 & . & 8 & 5.757 & 0,14 \\
\hline 1910 & & 13 & 6.246 & 0,21 \\
\hline 11 & $\cdots$ & 14 & 6.933 & 0,20 \\
\hline 12 & $\ldots \ldots$ & 20 & 8.585 & 0,23 \\
\hline 13 & $\cdots$ & 12 & 9.301 & 0,13 \\
\hline 14 & $\ldots$ & 12 & 8.491 & 0,14 \\
\hline 15 & $\ldots \ldots \ldots \ldots$ & 21 & 7.621 & 0,28 \\
\hline 16 & . & 18 & 8.176 & 0,22 \\
\hline 17 & $\ldots$ & 25 & 7.908 & 0,32 \\
\hline 18 & . & 27 & 14.811 & 0,18 \\
\hline 19 & $\ldots \ldots \ldots \ldots$ & 21 & 9.985 & 0,21 \\
\hline 1920 & & 22 & 10.565 & 0,21 \\
\hline 21 & & 28 & 11.252 & 0,25 \\
\hline 22 & & 41 & 11.473 & 0,36 \\
\hline 23 & & 37 & 12.292 & 0,30 \\
\hline 24 & . & 25 & 13.158 & 0,19 \\
\hline 25 & $\cdots \cdots$ & 29 & 13.765 & 0,21 \\
\hline 26 & $\ldots \ldots$ & 42 & 14.077 & 0,30 \\
\hline 27 & & 36 & 14.106 & 0,26 \\
\hline 28 & $\ldots \ldots$ & 55 & 14.770 & 0,37 \\
\hline 29 & $\ldots \ldots$ & 58 & 14.649 & 0,40 \\
\hline 1930 & $\ldots \ldots \ldots$ & 57 & 13.586 & 0,42 \\
\hline
\end{tabular}

(Continua) 


\begin{tabular}{|c|c|c|c|c|}
\hline & \multirow{2}{*}{$A n o$} & \multicolumn{2}{|c|}{ obitos } & \multirow{2}{*}{$\begin{array}{c}\text { Coeficientes de mor- } \\
\text { talidade proporciona } \\
(\%)\end{array}$} \\
\hline & & Diabetes melito & Tôdas as causas & \\
\hline 1931 & $\ldots$ & 63 & 13.633 & 0,46 \\
\hline 32 & $\ldots \ldots \ldots \ldots$ & 79 & 12.720 & 0,62 \\
\hline 33 & $\ldots \ldots \ldots \ldots$ & 74 & 14.576 & 0,51 \\
\hline 34 & $\ldots$ & 101 & 13.204 & 0.76 \\
\hline 35 & $\ldots \ldots \ldots \ldots$ & 120 & 14.984 & 0,80 \\
\hline 36 & $\ldots \ldots \ldots \ldots$ & 106 & 17.207 & 0,62 \\
\hline 37 & $\ldots \ldots \ldots \ldots$ & 126 & 15.923 & 0,79 \\
\hline 38 & $\ldots \ldots \ldots \ldots$ & 153 & 17.119 & 0,89 \\
\hline 39 & $\ldots \ldots \ldots \ldots$ & 140 & 17.887 & 0,78 \\
\hline 1940 & $\ldots \ldots \ldots \ldots$ & 143 & 17.116 & 0,84 \\
\hline 41 & $\ldots \ldots$ & 210 & 19.295 & 1,09 \\
\hline 42 & $\ldots \ldots \ldots \ldots$ & 204 & 19.145 & 1,06 \\
\hline 43 & $\ldots \ldots \ldots \ldots$ & 181 & 18.697 & 0,97 \\
\hline 44 & $\ldots$ & 206 & 20.128 & 1,02 \\
\hline 45 & $\ldots \ldots \ldots \ldots$ & 186 & 19.981 & 0,93 \\
\hline 46 & .. & 197 & 18.650 & 1,06 \\
\hline 47 & & 222 & 19.539 & 1,14 \\
\hline 48 & $\cdots$ & 246 & 21.093 & 1,17 \\
\hline 49 & $\ldots \ldots \ldots \ldots$ & 210 & 21.714 & 0,97 \\
\hline 1950 & $\cdots \cdots$ & 176 & 22.267 & 0.79 \\
\hline 51 & $\ldots$ & 251 & 23.794 & 1,05 \\
\hline 52 & $\cdots$ & 261 & 22.565 & 1,16 \\
\hline 53 & $\ldots \ldots$ & 354 & 24.188 & 1,46 \\
\hline 54 & $\ldots \ldots \ldots$ & 379 & 25.588 & 1,48 \\
\hline 55 & $\ldots \ldots$ & 416 & 27.819 & 1,50 \\
\hline 56 & $\ldots \ldots \ldots \ldots$ & 492 & 29.233 & 1,68 \\
\hline 57 & $\ldots \ldots$ & $\tilde{518}$ & 29.259 & 1,77 \\
\hline 58 & & 534 & 28.268 & 1,89 \\
\hline 59 & $\ldots$ & 639 & 30.438 & 2,10 \\
\hline 1960 & $\ldots \ldots \ldots \ldots$ & 675 & 31.958 & 2,11 \\
\hline
\end{tabular}

Fonte: Departamento de Estatística do Estado de São Paulo. 


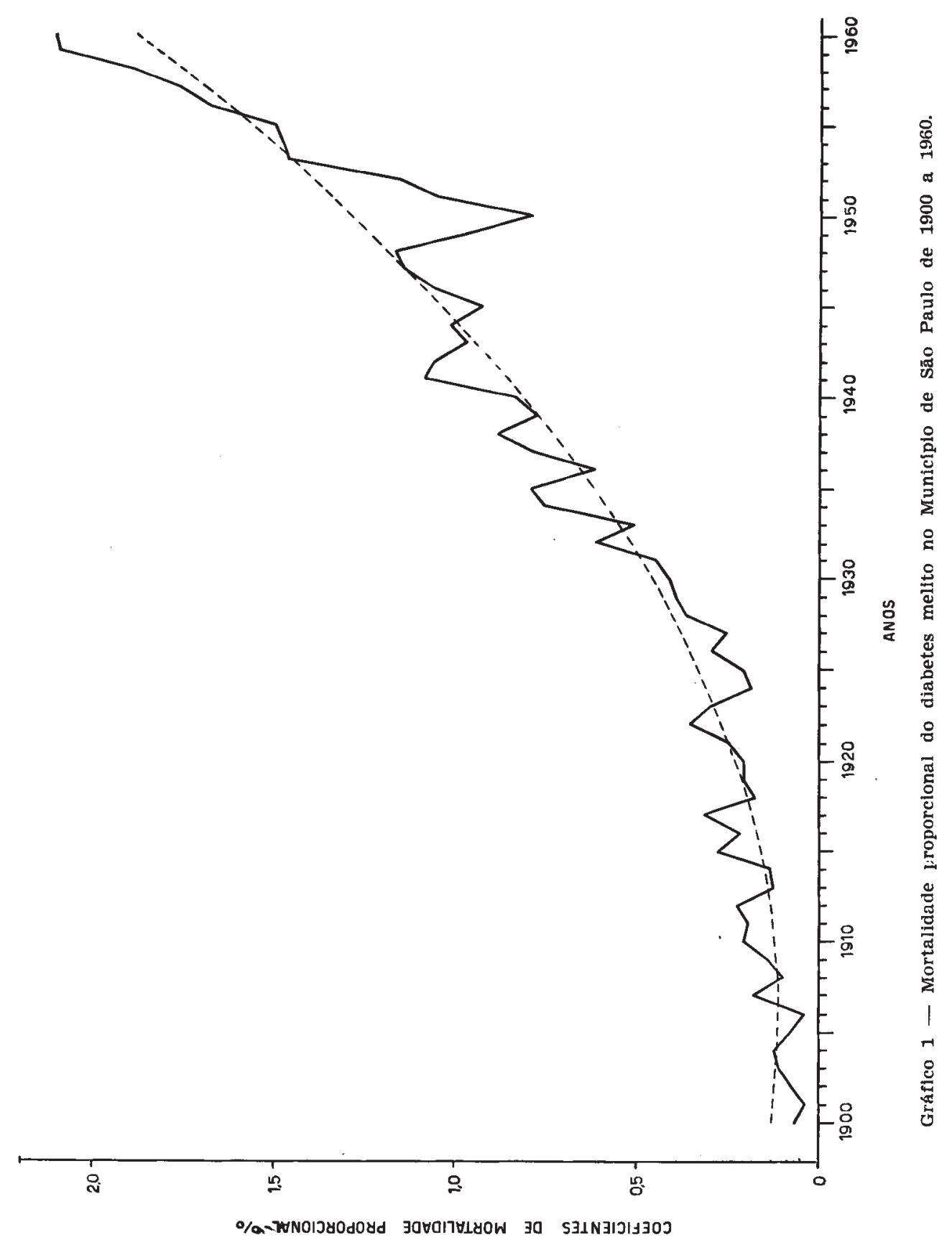


No ano de 1918 houve uma queda na mortalidade proporcional do diabetes melito, o que era de se esperar, devido à pandemia de influenza, que foi responsável por 5.372 óbitos dos 14.811 ocorridos por tôdas as causas. 0 coeficiente de mortalidade, entretanto, aumentou nesse mesmo ano, como veremos adiante.

Em 1949 encontramos uma queda acentuada na mortalidade proporcional do diabetes melito, que se acentua mais ainda em 1950, para voltar a seus níveis anteriores dois anos mais tarde e continuar a subir até 1960. Não encontramos explicação para êste fato, a não ser o acaso.

Entendemos de interêsse comparar a mortalidade proporcional do diabetes melito com a de outras doenças, através das chamadas dez principais causas de óbito. Agrupamos as causas de óbito segundo o sistema preconizado pela Organização Mundial de Saúde ${ }^{7}$ e fizemos a lista das dez principais no Município de São Paulo em 1960 (tabela 2 e gráfico 2). Podemos ver que nesse ano o diabetes melito foi a $10^{*}$

Tabela 2 - Dez principais causas de óbito no Município de São Paulo em 1960.

\begin{tabular}{|c|c|}
\hline Causas & $\begin{array}{l}\text { Coeficientes de mor- } \\
\text { talidade proporcional } \\
(\%)\end{array}$ \\
\hline 1 - Doenças do coração .... & 19,01 \\
\hline 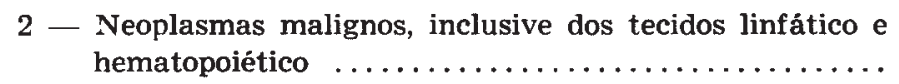 & 12,08 \\
\hline 3 - Lesões vasculares do sistema nervoso central. & 7,71 \\
\hline 4 - Pneumonia & 7,20 \\
\hline $\begin{array}{r}5 \text { - Gastrite, duodenite, enterite e colite, exceto diarréia } \\
\text { dos recém-nascidos } \ldots \ldots \ldots \ldots \ldots \ldots \ldots \ldots \ldots \ldots \ldots\end{array}$ & 5,82 \\
\hline 6 - Todos os acidentes & 4,29 \\
\hline 7 - Tuberculose ........... & 3,14 \\
\hline 8 - Infecções dos recém-nascidos & 2,81 \\
\hline $\begin{array}{r}9-\text { Lesōes devidas ao parto, asfixia e atelectasia pós- } \\
\text { natais } \ldots \ldots \ldots \ldots \ldots \ldots \ldots \ldots \ldots \ldots \ldots \ldots \ldots\end{array}$ & 2,80 \\
\hline $10-$ Diabetes melito $\ldots \ldots \ldots \ldots \ldots \ldots \ldots \ldots \ldots \ldots$ & 2,11 \\
\hline
\end{tabular}

Fonte: Departamento de Estatística do Estado de São Paulo. 


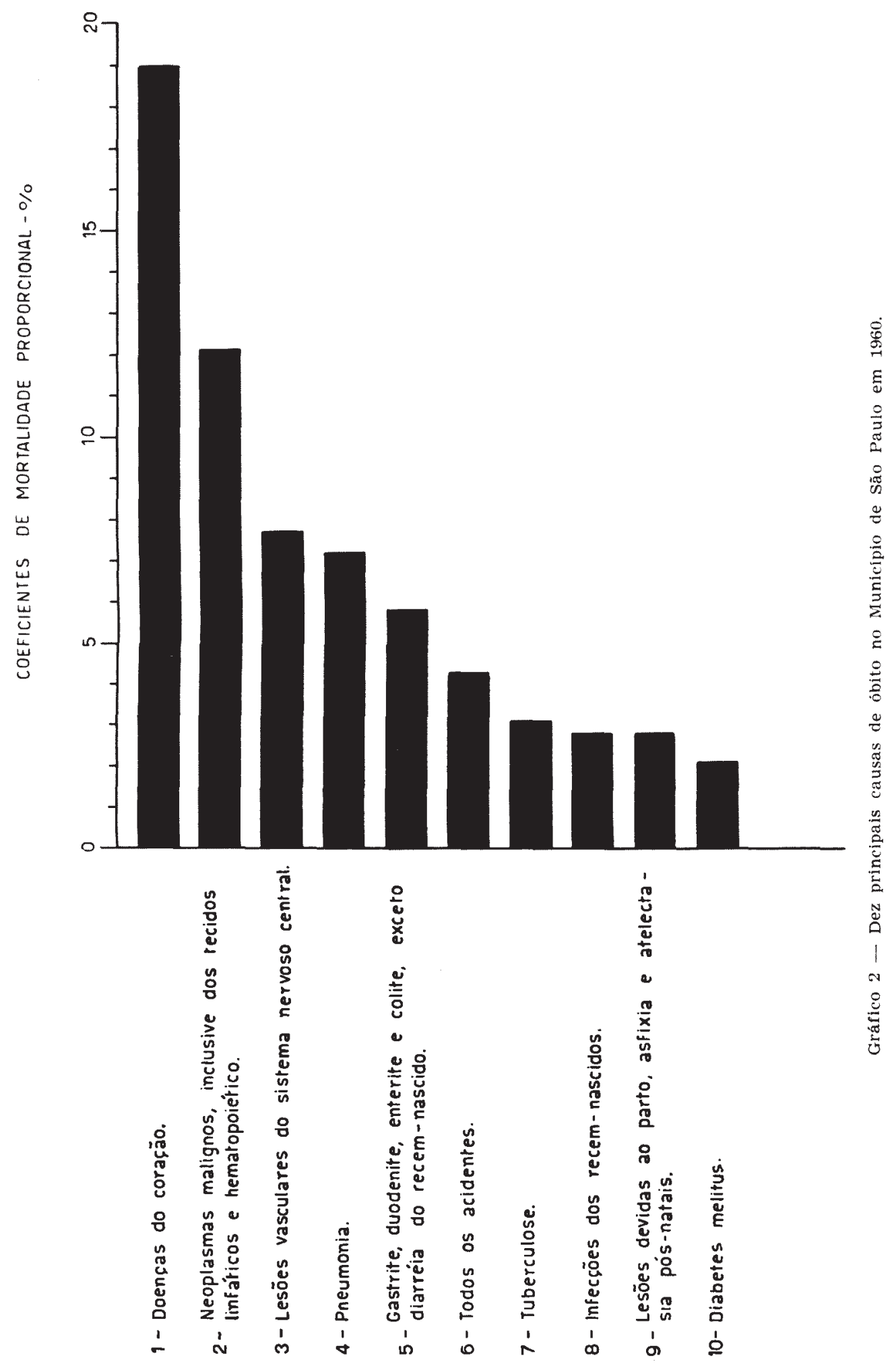


causa de óbito. Mostra isto que esta doença tem grande importância como causa de óbito entre nós, e que essa importância vem aumentando progressivamente, pois era a 55a causa em 1900, como já ficou dito.

Compararemos, a seguir, o que ocorre no Município de São Paulo, em relação à mortalidade proporcional do diabetes melito, com o que ocorre em outros países da América e do mundo. A Organização Muncial de Saúde publica, em seu Rapport Épidémiologique et Démographi$q u e^{7}$ as dez principais causas de óbito em 12 países no período de 1954 a 1956. Dessa publicação verificamos que o diabetes melito ocupa um lugar entre as dez principais causas de óbito em 8 dos 12 países. Os coeficientes de mortalidade proporcional por diabetes melito nesses países, assim como no Município de São Paulo para o mesmo período, estão resumidos na tabela 3. A Organização Pan-Americana de Saúde, Agência Regional da Organização Mundial de Saúde para as Américas, publicou em junho de 1958 o "Four-year Reports on Health Conditions in the Americas", no qual dá os óbitos referentes às causas especificadas na classificação internacional de doenças e causas de morte para vários países das Américas ${ }^{11}$, nos anos de 1956 para alguns, de

Tabela 3 - Mortalidade proporcional do diabetes melito em vários países e no Município de São Paulo (1954-1956).

\begin{tabular}{|c|c|}
\hline$R e g i \tilde{o} e s$ & $\begin{array}{l}\text { Coeficientes de mor- } \\
\text { talidade proporcional } \\
\qquad \%)\end{array}$ \\
\hline Estados Unidos da América do Norte & 1,7 \\
\hline Paises Baixos & 1,6 \\
\hline Município de São Paulo & 1,5 \\
\hline Austrália & 1,4 \\
\hline Suiça $\ldots . . .$. & 1,4 \\
\hline Canadá & 1,3 \\
\hline Suécia $\ldots \ldots \ldots$ & 1,1 \\
\hline Alemanha (República Federal) & 1,0 \\
\hline França $\ldots \ldots \ldots \ldots$ & 1,0 \\
\hline
\end{tabular}


1955 para outros e de 1953 para outros ainda. Selecionamos 13, incluindo o Brasil, ao acaso, procurando representar as três Américas e excluindo aquêles países cujos dados se referem a 1953, e calculamos os coeficientes de mortalidade proporcional. Êstes coeficientes, assim como a posição do diabetes melito em relação às outras causas e o ano a que se referem os dados, estão representados na tabela 4 .

TABELA 4 - Coeficientes de mortalidade proporcional do diabetes melito e lugar que ocupa em relação às demais causas de óbito em alguns países das Américas e Município de São Paulo.

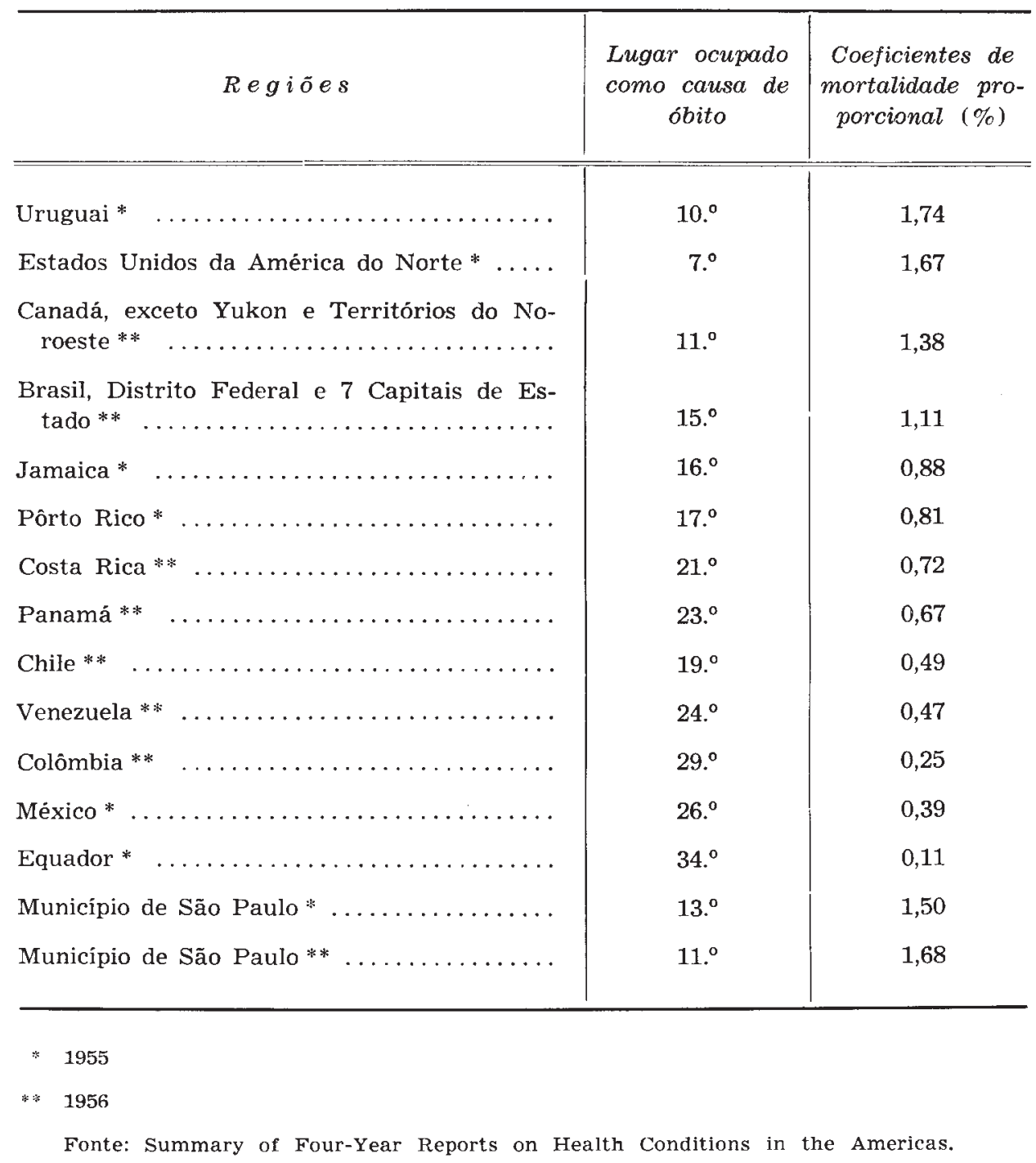


Verificamos que o Brasil tem um coeficiente de mortalidade proporcional (referente apenas ao Distrito Federal - atual Estado da Guanabara - e 7 capitais de Estado) inferior apenas aos do Uruguai, Estados Unidos da América do Norte e Canadá. O coeficiente do Município de São Paulo, em 1955, é inferior, apenas, aos dos Estados Unidos da América do Norte e do Uruguai (ambos para êsse ano). Nos Estados Unidos da América do Norte e Uruguai, a doença figura entre as dez principais causas de óbito, e no Canadá é a 11: Devemos lembrar que o coeficiente de mortalidade proporcional do Canadá não inclui os Territórios do Noroeste e Yukon, o que vem viciá-lo. Quanto ao Brasil, o coeficiente também é viciado, pois se refere apenas a 8 municípios, incluindo o de São Paulo. Por outro lado, dos 791 óbitos por diabetes melito ocorridos nesses 8 municípios, 416 ocorreram no de São Paulo, ou seja, 52,59\%; dos 71.158 óbitos por tôdas as causas ocorridos nos mesmos 8 municípios, 27.819 , ou seja, 39,09\%, ocorreram em São Paulo. Pela desproporção entre os óbitos por diabetes melito $(52,59 \%)$ e os por tôdas as causas $(39.09 \%)$ podemos ver quanto o Município de São Paulo eleva o coeficiente do País.

MORTALIDADE POR DIABETES MELITO NO PERIODO DE 1900 A 1960

Verificamos que a mortalidade proporcional do diabetes melito aumentou de 1900 a 1960. Êste aumento pode ser explicado por uma queda na mortalidade por outras causas e por um aumento na mortalidade por diabetes melito. Mostramos, em trabalho anterior, que o primeiro fato ocorreu em nosso Município ${ }^{12}$. Neste trabalho verificamos que o segundo fato, também, ocorreu, como podemos ver pela tabela 5 e pelo gráfico 3. Como acontece em tôdas as doenças, a curva de mortalidade é uma linha quebrada. Com os pontos desta linha e a equação da reta, podemos ajustar uma reta à nossa linha quebrada, e que será a tendência da mortalidade. Sendo a equação da linha reta $y=a+b x$, encontramos para $a$ o valor de 0,71848 e para $b$ o de 0,02345 , passando nossa reta a ser $y=0,71848+0,02345 x$. Esta reta está traçada no gráfico 3 e mostra uma tendência crescente da mortalidade por diabetes melito.

Já dissemos, anteriormente, que cresceu, acentuadamente, a vida média no nosso Município, especialmente nos últimos anos. Como o djabetes melito é uma doença que se manifesta preferentemente depois dos 50 anos, talvez o aumento da vida média possa ser responsável pelo aumento da mortalidade. Podemos, entretanto, eliminar dos nossos coeficientes o efeito da idade, padronizando-os segundo uma população es- 
WILSON, D. - MORTALIDADE POR DIABETES MELITO...

45

TABeLA 5 - Mortalidade por diabetes melito no Município de São Paulo 1900 a 1960.

\begin{tabular}{|c|c|c|c|c|c|}
\hline Anos & $\begin{array}{c}\text { Número de } \\
\text { óbitos }\end{array}$ & $\begin{array}{l}\text { Coeficientes de } \\
\text { mortalidade por } \\
100.000 \text { hab. }\end{array}$ & Anos & $\begin{array}{l}\text { Número de } \\
\text { óbitos }\end{array}$ & $\begin{array}{l}\text { Coeficientes de } \\
\text { mortalidade por } \\
100.000 \text { hab. }\end{array}$ \\
\hline 1900 & 3 & 1,30 & 1931 & 63 & 6,95 \\
\hline 01 & 2 & 0,81 & 32 & 79 & 8,36 \\
\hline 02 & 4 & 1,58 & 33 & 74 & 7,52 \\
\hline 03 & 5 & 1,77 & 34 & 101 & 9,84 \\
\hline 04 & 6 & 2,00 & 35 & 120 & 11,22 \\
\hline 05 & 4 & 1,26 & 36 & 106 & 9,51 \\
\hline 06 & 2 & 0,60 & 37 & 126 & 10,85 \\
\hline 07 & 9 & 2,50 & 38 & 153 & 12,64 \\
\hline 08 & 6 & 1,63 & 39 & 140 & 11,10 \\
\hline 09 & 8 & 2,07 & 1940 & 143 & 10,87 \\
\hline 1910 & 13 & 3,23 & 41 & 210 & 15,17 \\
\hline 11 & 14 & 3,33 & 42 & 204 & 14,00 \\
\hline 12 & 20 & 4,57 & 43 & 181 & 11,80 \\
\hline 13 & 12 & 2,64 & 44 & 206 & 12,76 \\
\hline 14 & 12 & 2,54 & 45 & 186 & 10,94 \\
\hline 15 & 21 & 4,29 & 46 & 197 & 11,01 \\
\hline 16 & 18 & 3,56 & 47 & 222 & 11,78 \\
\hline 17 & 25 & 4,78 & 48 & 246 & 12,40 \\
\hline 18 & 27 & 5,00 & 49 & 210 & 10,06 \\
\hline 19 & 21 & 3,77 & 1950 & 176 & 8,01 \\
\hline 1920 & 22 & 3,83 & 51 & 251 & 10,85 \\
\hline 21 & 28 & 4,67 & 52 & 261 & 10,71 \\
\hline 22 & 41 & 6,57 & 53 & 354 & 13,80 \\
\hline 23 & 37 & 5,68 & 54 & 379 & 14,04 \\
\hline 24 & 25 & 3,69 & 55 & 416 & 14,11 \\
\hline 25 & 29 & 4,10 & 56 & 492 & 15,73 \\
\hline 26 & 42 & 5,70 & 57 & 518 & 15,61 \\
\hline 27 & 36 & 4,69 & 58 & 534 & 15,16 \\
\hline 28 & 55 & 6,87 & 59 & 639 & 17,09 \\
\hline 29 & 58 & 6,95 & 1960 & 675 & 17,01 \\
\hline 1930 & 57 & 6,56 & & & \\
\hline
\end{tabular}

Fonte: Departamento de Estatística do Estado de São Paulo. 


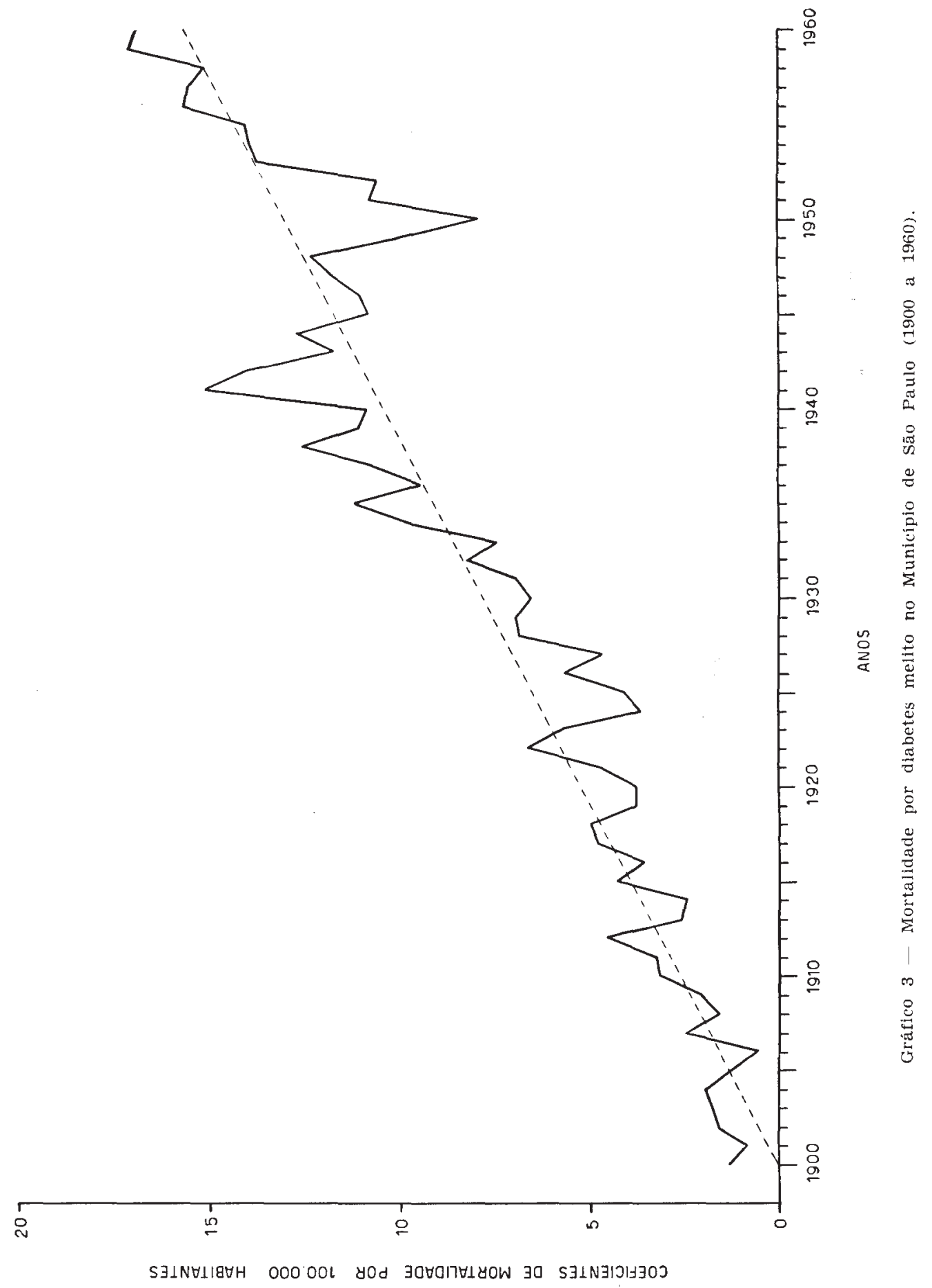


colhida como padrão. Padronizamos nossos coeficientes para os anos de $1920,1930,1940$ e'1960 segundo a população de 1950, utilizando o método direto de padronização. Pela tabela 6, podemos ver que os coeficientes dos anos anteriores a 1950 aumentaram com a padronização, enquanto que o de 1960 diminuiu; as modificações, entretanto, não foram de grande monta, permitindo-nos concluir que existem fatôres mais importantes que o envelhecimento da população, fazendo crescer a mortalidade por diabetes melito. O gráfico 4 mostra os coeficientes da tabela 6.

Existe uma relação teórica entre letalidade, mortalidade e morbidade, que é a seguinte:

Cceficiente de mortalidade $=$ Coeficiente de letalidade $\times$ Coeficiente de morbidade.

Vemos, por esta relação, que a mortalidade varia diretamente com variaç̃̃es tanto da morbidade como com variações da letalidade. Parece-nos, entretanto, que a letalidade do diabetes melito diminuiu nos últimos anos, em virtude da melhor terapêutica. Breslow ${ }^{2}$ nos mostra a expectativa de vida do diabético aos 10 e aos 50 anos de idade, nos períodos de 1897 a 1914, de 1922 a 1926 e de 1939 a 1945 e a expectativa de vida da população geral, nas mesmas idades, para o período de 1939 a 1941 (gráfico 5). Os dados utilizados são do "George F.

TAbela 6 - Mortalidade por diabetes melito no Município de São Paulo nos anos de 1920, 1930, 1940, 1950 e 1960 (coeficientes de mortalidade por 100.000 habitantes e coeficientes de mortalidade padronizados segundo a população de 1950).

\begin{tabular}{|c|c|c|}
\hline$A n \circ s$ & $\begin{array}{l}\text { Coeficientes de mortalidade } \\
\text { por } 100.000 \text { habitantes }\end{array}$ & $\begin{array}{c}\text { Coeficientes de mortalidade } \\
\text { por 10o.ooo habitantes, pa- } \\
\text { dronizados }\end{array}$ \\
\hline 1920 & 3,83 & 4,49 \\
\hline $1930 \ldots$ & 6,56 & 7,59 \\
\hline $1940 \ldots$ & 10,87 & 11,23 \\
\hline 1950 & 8,01 & 8,01 \\
\hline $1960 \ldots$ & 17,01 & 16,38 \\
\hline
\end{tabular}



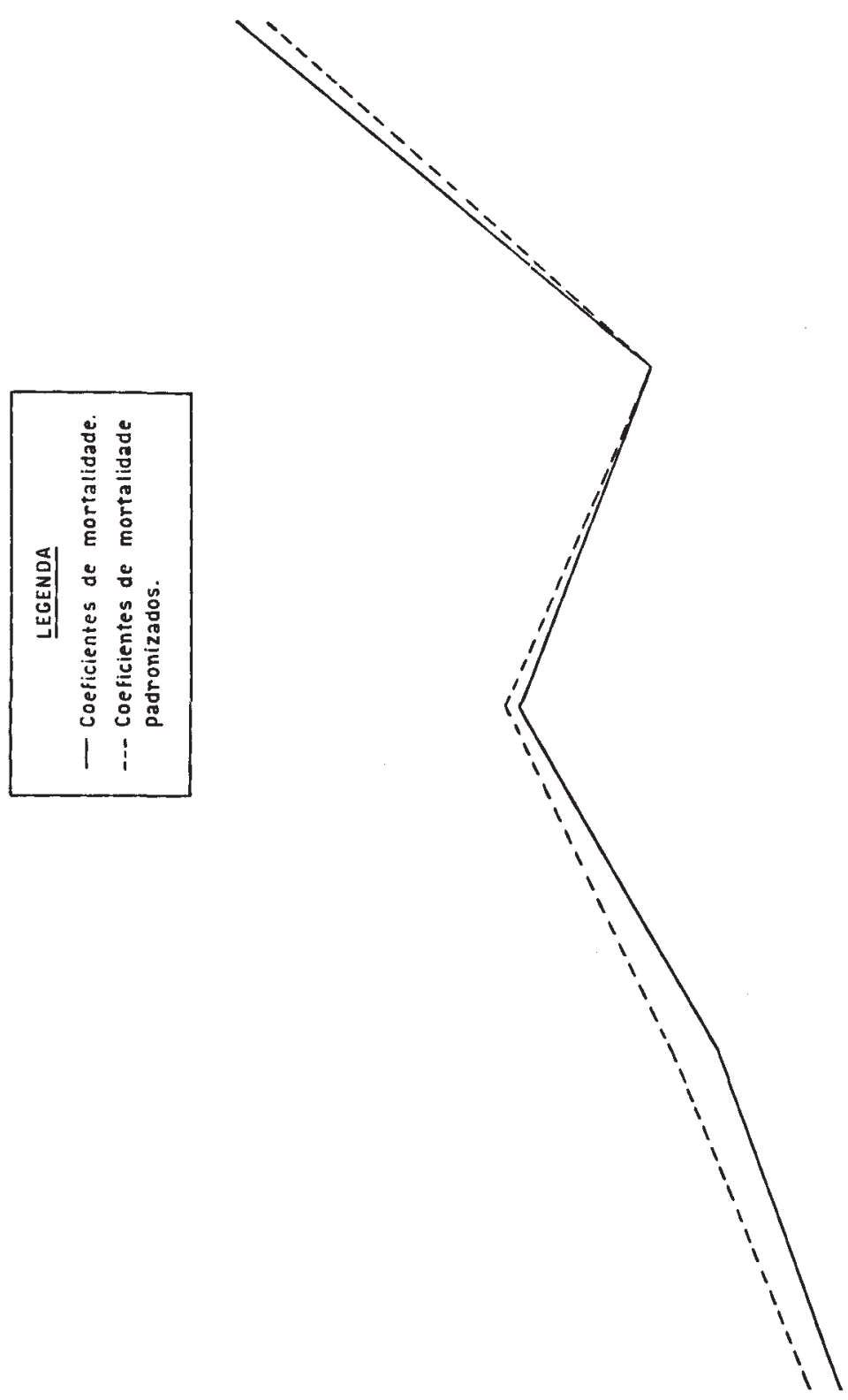

$[\stackrel{\circ}{\circ}$

焉

\&

(.

煦 $\frac{\pi}{3}$

일

क्ष

只

के

용

है ํํํ

을 을

올

号 음

ชิ

$\stackrel{0}{\circ}$

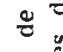

온

:

帘

0

:

응

芴

है

总

要

๕.

ชั

莺

密

$\sum \stackrel{\Sigma}{0}$

I है

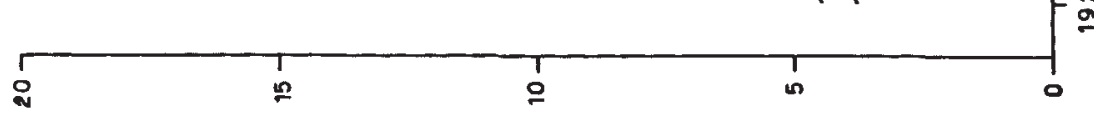

胥 

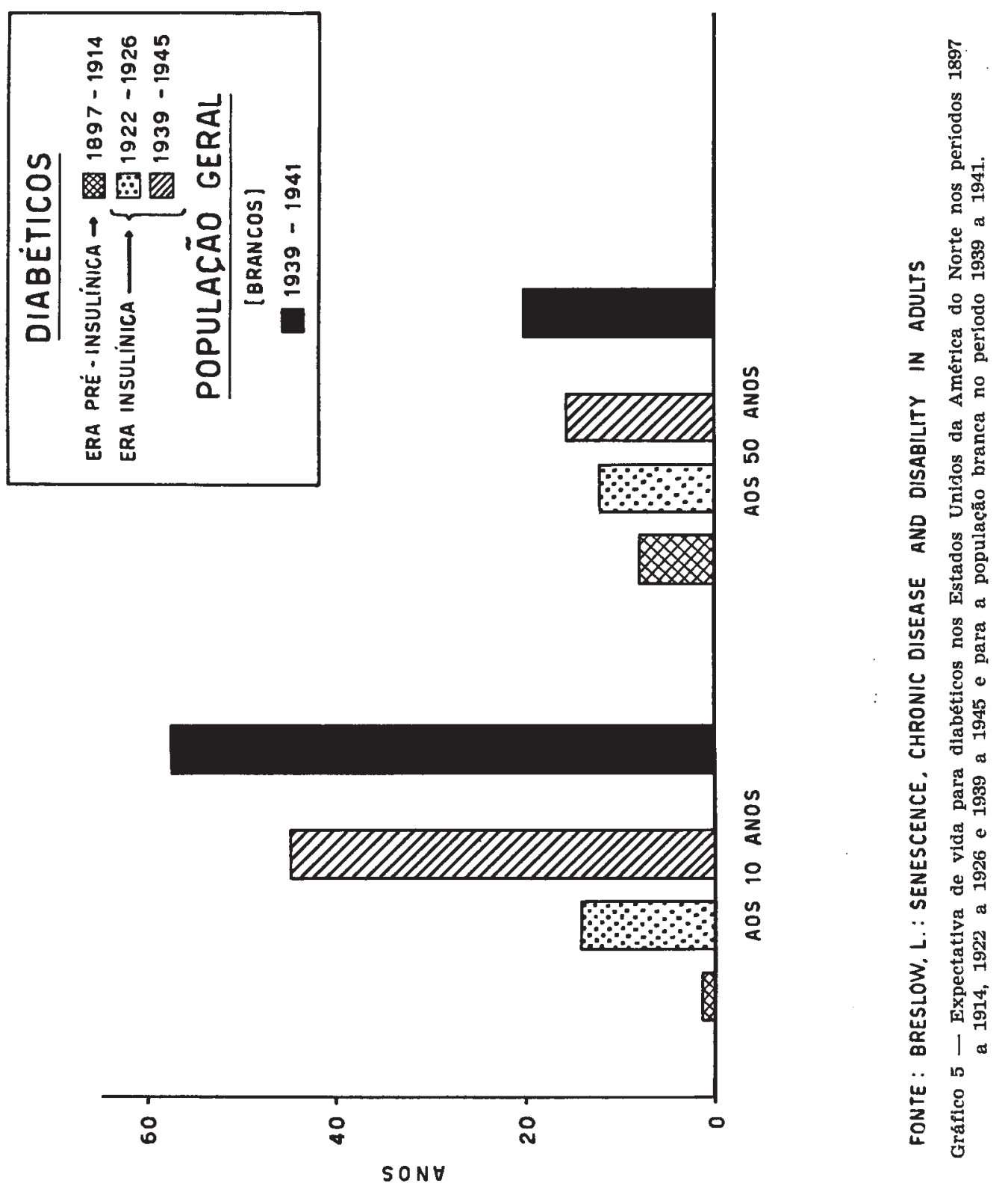
Baker Clinic for Diabetics", Boston, Massachusetts, Estados Unidos da América do Norte. Vemos que a expectativa de vida, em ambas as idades, aumentou para os diabéticos, no correr dos anos, embora não tanto quanto o da população geral.

$\mathrm{Na}$ impossibilidade de calcularmos a expectativa de vida de diabéticos entre nós, procuramos verificar qual o percentual dos óbitos por diabetes melito ocorrido em cada grupo etário. Para isso agrupamos os vários anos em quatro decênios: 1918 a 1927; 1928 a 1937; 1938 a $1947 ; 1948$ a 1957 . Na tabela 7 vemos que houve um deslocamento dos percentuais em direção aos grupos etários mais velhos, o que pode ser melhor visto no gráfico 6. Calculamos, também, o percentual de óbitos ccorridos nos grupos de 0 a 59 anos e 60 anos e mais. Os resultados estão na tabela 8 e no gráfico 7. Por êles podemos ver que as proporções correspondentes aos grupos de 60 anos e mais são cada vez maicres. Êste fato nos leva a crer que entre nós, também, houve um aumento na expectativa de vida dos diabéticos; a expectativa de

TABELA 7 - Distribuição etária percentual dos óbitos por diabetes melito ocorridos no Município de São Paulo nos decênios de 1918 a 1927, 1928 a 1937, 1938 a 1947 e 1948 a 1957.

\begin{tabular}{|c|c|c|c|c|}
\hline \multirow{2}{*}{$\begin{array}{c}\text { Grupos etários } \\
\text { (anos) }\end{array}$} & \multicolumn{4}{|c|}{ Percentuais de óbitos por diabetcs melito } \\
\hline & $\begin{array}{c}1918 \text { a } 1927 \\
(\%)\end{array}$ & $\begin{array}{c}1928 \text { a } 1937 \\
(\%)\end{array}$ & $\begin{array}{c}1938 \text { a } 1947 \\
(\%)\end{array}$ & $\begin{array}{c}1948 \text { a } 1957 \\
(\%)\end{array}$ \\
\hline 0 a $9 \ldots \ldots \ldots$ & 2,27 & 0,72 & 0,65 & 0,36 \\
\hline 10 a $19 \ldots$ & 3,90 & 1,55 & 1,57 & 1,18 \\
\hline 20 a $29 \ldots$ & 7,79 & 4,29 & 2,12 & 1,73 \\
\hline 30 a 39 & 4,55 & 5,84 & 4,18 & 2,66 \\
\hline 40 a $49 \ldots$ & 10,39 & 11,44 & 8,85 & 7,78 \\
\hline 50 a $59 \ldots$ & 28,57 & 23,12 & 21,44 & 19,89 \\
\hline 60 a $69 \ldots$ & 25,00 & 31,23 & 32,20 & 33,22 \\
\hline 70 a $79 \ldots$ & 16,56 & 18,58 & 23,24 & 25,34 \\
\hline 80 e $+\ldots \ldots$ & 0,97 & 3,22 & 5,75 & 7,78 \\
\hline
\end{tabular}

Fonte: Departamento de Estatistica do Estado de São Paulo. 
PERCENTUAIS

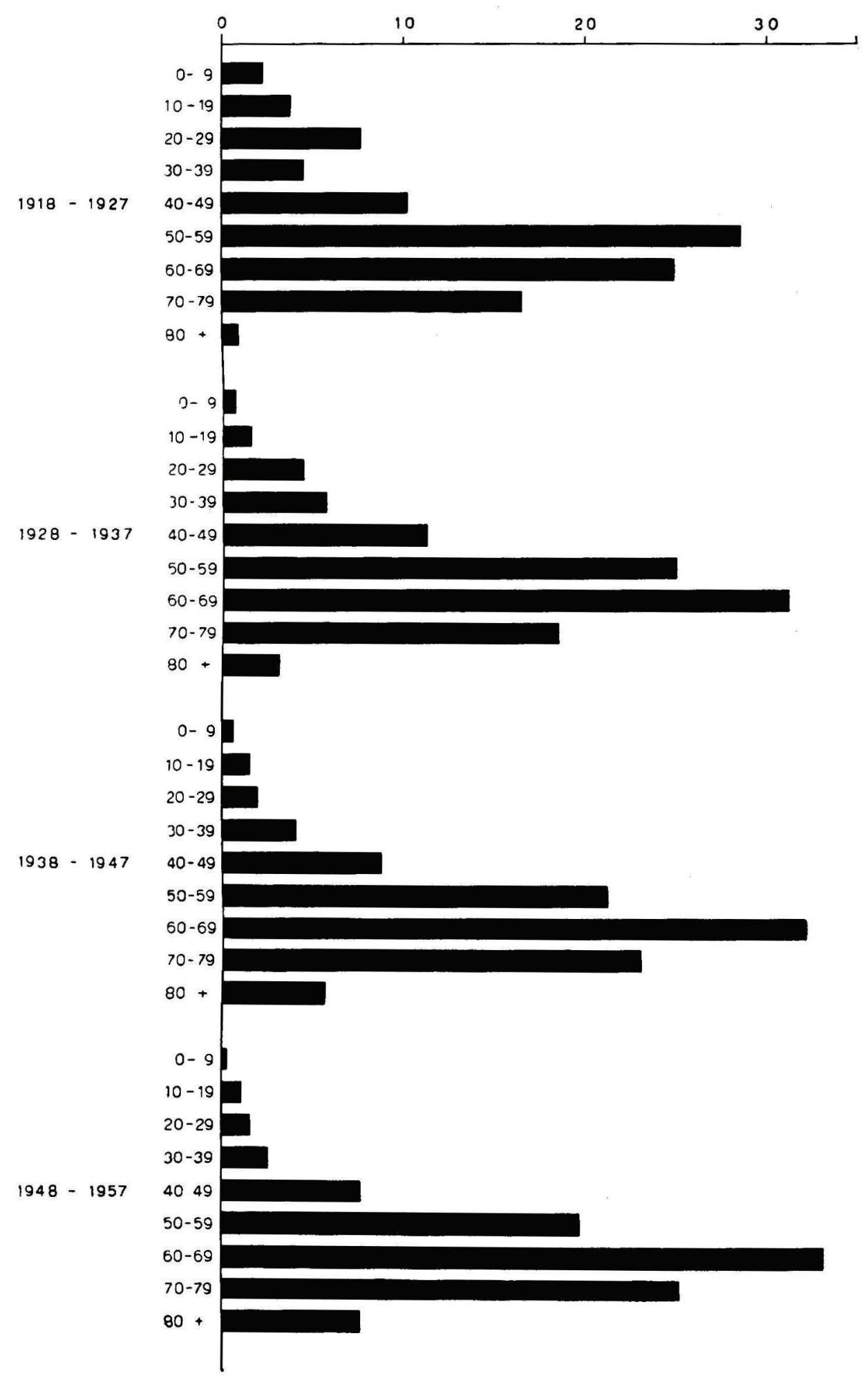

Gráfico 6 - Distribuição etária percentual dos óbitos por diabetes melito ocorridos no Municipio de São Paulo nos decênios de 1918 a 1927, 1928 a 1937, 1938 a 1947 e 1948 a 1957. 
Tabela 8 - Distribuição percentual dos óbitos dos diabetes melito nos grupos etários de 0 a 59 anos e 60 anos e mais no Município de São Paulo nos decênios 1918 a 1927, 1928 a 1937, 1938 a 1947 e 1948 a 1957.

\begin{tabular}{c|c|c|c|c}
\hline \multirow{2}{*}{$\begin{array}{c}\text { Grupoe etários } \\
(\text { anos })\end{array}$} & $\begin{array}{c}\mid 4 \\
1918 \text { a } 1927 \\
(\%)\end{array}$ & $\begin{array}{c}1928 \text { a } 1937 \\
(\%)\end{array}$ & $\begin{array}{c}1938 \text { a } 1947 \\
(\%)\end{array}$ & $\begin{array}{c}1948 \text { a } 1957 \\
(\%)\end{array}$ \\
\cline { 2 - 5 } & 57,47 & 46,96 & 38,81 & 33,66 \\
60 e $+\ldots \ldots \ldots \ldots \ldots$ & 42,53 & 53,04 & 61,19 & 66,34 \\
\hline
\end{tabular}

Fonte: Departamento de Estatística do Estado de São Paulo.

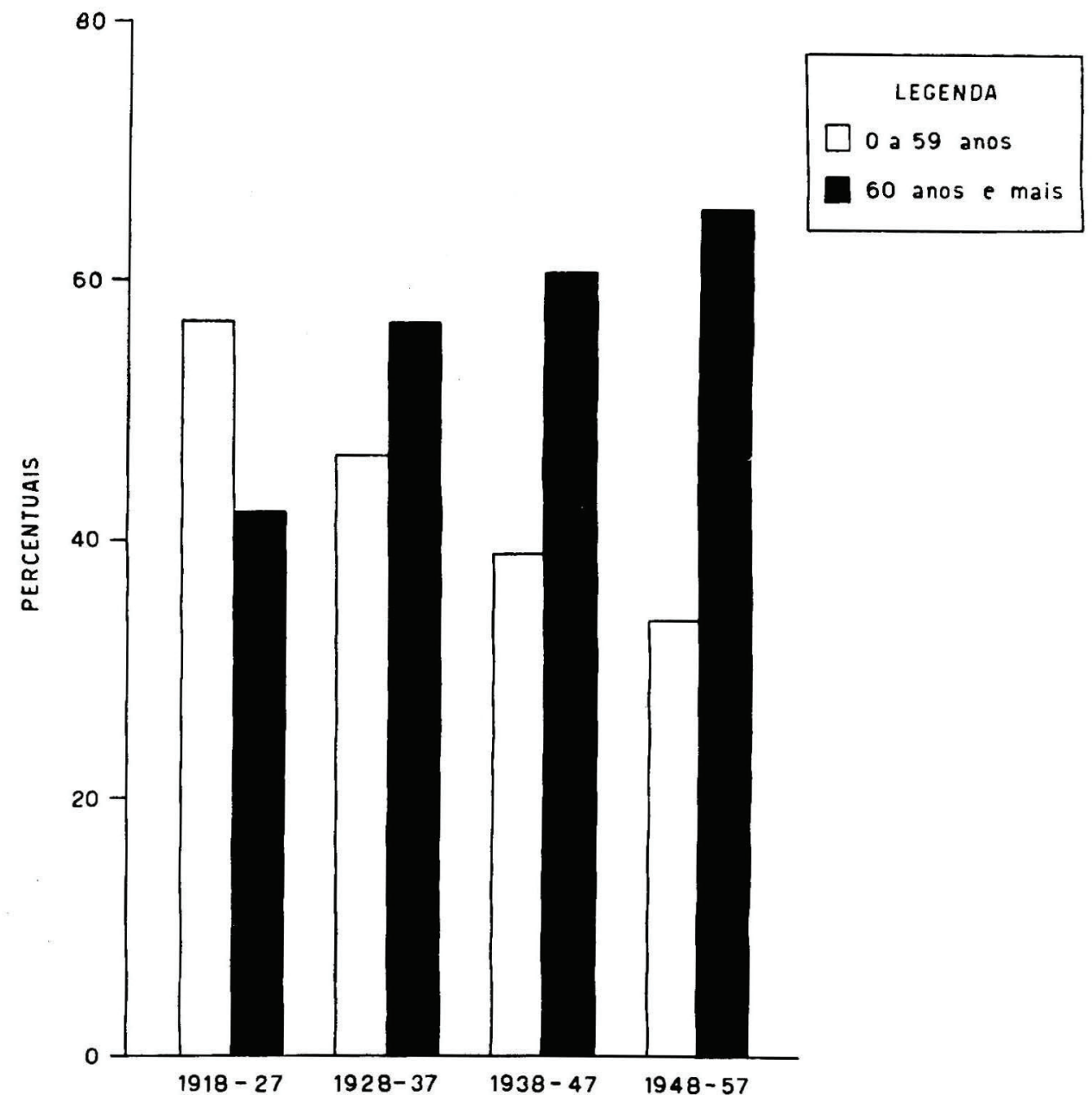

Gráfico 7 - Distribuicão percentual dos óbitos por diabetes melito nos grupos etários de 0 a 59 anos e 60 anos e mais no Municipio de São Paulo nos decênios 1918 a 1927, 1928 a 1937,1938 a 1947 e 1948 a 1957. 
vida varia inversamente com a letalidade, o que nos leva a crer, pela relação mencionada à página 47 , que houve um aumento na morbidade.

Seria interessante comparar o Município de São Paulo com outros países do mundo. Vemos na tabela 9 os coeficientes de mortalidade por diabetes melito em vários países e no Município de São Paulo. Ao escolhermos os países procuramos representar todos os continentes e procuramos excluir aquêles cujos dados recentes não fossem conhecidos ainda. A inspeção da tabela 9 nos mostra que sòmente um país tem coeficientes mais altos que os da nossa Capital: Estados Unidos da América do Norte e, mesmo assim, não em todos os anos. Em 1955, 1957 e 1958 são maiores, em 1956 o nosso e o norte-americano são iguais, ao passo que em 1959 o coeficiente norte-americano é menor que o do Município de São Paulo.

TABELA 9 - Mortalidade por diabetes melito em vários países e no Município de São Paulo (1955 a 1959).

\begin{tabular}{|c|c|c|c|c|c|}
\hline \multirow{2}{*}{ Países } & \multicolumn{5}{|c|}{$\begin{array}{c}\text { Coeficientes de mortalidade por } 100.000 \\
\text { habitantes }\end{array}$} \\
\hline & 1955 & 1956 & 1957 & 1958 & 1959 \\
\hline Canadá .... & 11,0 & 11,3 & 11,2 & 11,0 & 11,4 \\
\hline Colômbia $\quad \ldots$ & 3,3 & $\mathbf{3 , 3}$ & 3,6 & 4,3 & 4,5 \\
\hline Estados Unidos da América do Norte & 15,5 & 15,7 & 16,0 & 15,9 & 15,7 \\
\hline República Federal Alemã & 10,5 & 11,6 & 11,9 & 11,8 & * \\
\hline China Nacionalista ...... & 1,6 & 1,6 & 1,6 & 1,9 & 1,9 \\
\hline Israel (população judia) & 3,3 & 3,7 & 4,3 & 2,7 & 3,1 \\
\hline Japão $\ldots \ldots \ldots \ldots \ldots$ & 2,5 & 2,8 & 3,0 & 2,9 & 3,0 \\
\hline França $\ldots$. & 11,8 & 12,7 & 12,1 & 12,1 & 11,5 \\
\hline Itália $\ldots \ldots \ldots \ldots \ldots$ & 11,1 & 11,8 & 12,3 & 10,7 & $*$ \\
\hline Inglaterra e Gales & 7,4 & 7,3 & 7,0 & 7,3 & 7,0 \\
\hline Suécia .... & 9,9 & 10,1 & 11,3 & 10,9 & * \\
\hline Suíça $\ldots . . . \ldots \ldots$. & 13,9 & 13,9 & 12,6 & 12,4 & * \\
\hline Austrália & 12,3 & 12,9 & 11,9 & 11,3 & 11,1 \\
\hline Municipio de São Paulo & 14,1 & 15,7 & 15,6 & 15,2 & 17,1 \\
\hline
\end{tabular}

* Dados ainda nāo disponiveis.

Fonte: Rapport Épidémiologique et Démographique, 14(1):21. 
MORTALIDADE SEGUNDO A IDADE NO PERfODO DE 1918 A 1957

A distribuição etária da mortalidade por diabetes melito também mudou com o tempo, conforme tivemos ensejo de mencionar páginas atrás. Não nos foi possível colhêr dados segundo a idade em época anterior a 1918, pois, embora exista a distribuição etária desde 1903, a divisão em grupos etários é diferente da que se usa de 1918 em diante, prejudicando grandemente as comparações. Como o número de anos e o número de grupos etários são grandes, não foi possível estudar a mortalidade segundo êste atributo ano a ano. Agrupamos, então, nossos dados em quatro períodos de dez anos e calculamos coeficientes médios. Nossos grupos etários não são iguais entre si, pois o primeiro compreende 40 anos e o último tem um limite superior infinito, ao passo que os demais são de dez anos. A explicação dêste fato é que não poderíamos estabelecer um nível superior fixo para o último grupo e os grupos de 0 a 9 , de 10 a 19 , de 20 a 29 e de 30 a 39 apresentam um número muito pequeno de óbitos, de modo a tornar os dados inconsistentes, levando-nos a juntá-los em um único grupo. Tomamos o período de 1918 a 1957 pelo que foi exposto acima e porque optamos por tomar decênios seguidos em virtude de os números do decênio 1948 a 1957 serem muito próximos dos do período 1958 a 1960 . Nosso primeiro decênio, 1918 a 1927, está, pràticamente, na era pré-insulínica,

Tabela 10 - Mortalidade por diabetes melito segundo a idade, por decênios, no Município de São Paulo no período de 1918 a 1957.

\begin{tabular}{|c|c|c|c|c|c|c|c|c|}
\hline \multirow{2}{*}{$\begin{array}{c}\text { Grupos } \\
\text { etários } \\
\text { (anos) }\end{array}$} & \multicolumn{2}{|c|}{1918 a 1927} & \multicolumn{2}{|c|}{1928 a 1937} & \multicolumn{2}{|c|}{1938 a 1947} & \multicolumn{2}{|c|}{1948 a 1957} \\
\hline & óbitos & Coef.* & óbitos & Coef.* & Obitos & Coef.* & óbitos & Coef.* \\
\hline 0 a 39 & 57 & 1,10 & 104 & 1,36 & 157 & 1,33 & 196 & 1,00 \\
\hline 40 a 49 & 32 & 5,57 & 96 & 9,92 & 163 & 9,89 & 257 & 8,75 \\
\hline 50 a 59 & 88 & 22,84 & 194 & 32,54 & 395 & 40,63 & 657 & 36,95 \\
\hline 60 a 69 & 77 & 40,18 & 262 & 85,68 & 593 & 117,14 & 1.097 & 120,09 \\
\hline 70 a 79 & 51 & 81,32 & 156 & 137,17 & 428 & 217,16 & 837 & 254,72 \\
\hline $80 \mathrm{e}+$ & 3 & 19,33 & 27 & 92,59 & 106 & 197,76 & 257 & 256,65 \\
\hline Ignorada & - & $\ldots$ & - & - & - & - & 2 & $\cdots$ \\
\hline
\end{tabular}

* Coeficientes médios de mortalidade por 100.000 habitantes.

Fonte: Departamento de Estatística do Estado de São Paulo. 
COEFICIENTES DE MORTALIDADE POR 100.000 HABITANTES

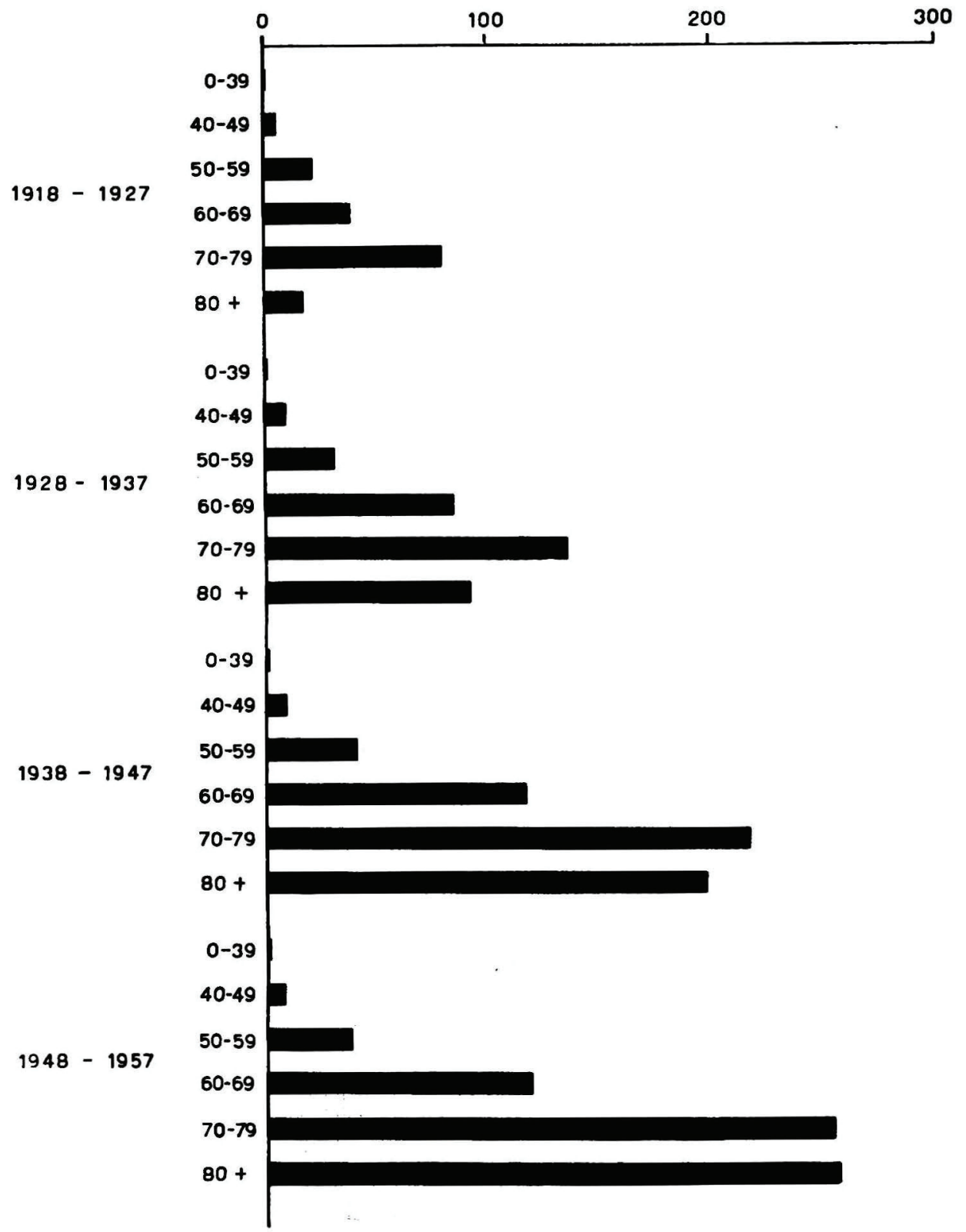

Gráfico 8 - Mortalidade por diabetes melito segundo a idade, por decênios, no Municipio de São Paulo, no periodo de 1918 a 1957. 
entre nós: o segundo, já conta com insulina; no tereceiro aparecem asinsulinas de ciepósito; no quarto a influencia das insulinas muito aperleiçoadas e, nos últimos anos, a dos agentes hipoglicemiantes orais se laz sentir. Vemos, pelos dados da tabela 10 e do grálico $x$, que a proporção de óbitos por 100.000 habitantes, no primeiro grupo etálio, é muito pequena (cêrca de 1) em torlos os periodos, mostrando que. embora a mortalidade tenha aumentado, èste grupo foi pouco atingido. Se considerarmos a mortalidale entre 10 a 59 anos, por um lado. o acima clos 60 anos, por outro, veremos que a mortalidade nestes últimos grupos aumentou muito mais que nos primeiros. O grupo que mais chama a atenção é o de 80 anos e mais, cujo coeficiente de 19,:3i:3, no primeiro decênio, passou a 256,65 no último, suplantando, ạui, us de todos os demais grupos. Isto se prende, provivelmente, ì maior longevidade do diabético, nos últimos anos, devido a melhor tratame'nto. Contando com agentes terapêticos mais eficientes, isto cra de ste esperar. Não devemos esquecer, entretanto, de outros fatores que vieram melhorar a terapêutica desta doença, como técnicas laboratoriais mais fáceis e mais rápidas, facilitando o contrôle; antibióticos, quue vieram a diminuir grandemente o risco das infecçōes, verdadeiro pesadêlo do diabético na era pré-antibiótica, ete.

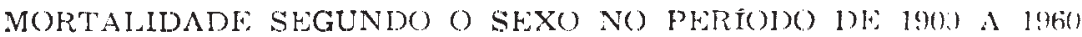

Aceita-se, quase universalmente, que o diabetes melito é muito mais freqüente na mulher do que no homem t. Assim sendo, não è surpreendente que haja maiores coeficientes de mortalidade no sexo feminino. Segundo Forsham e Thorn', morrem rluas rères mais muIheres do que homens por esta doença na sexta décarla da vida.

Observanclo a tabela 11 e o gráfico 9, podemos ver qute, no início do século, não havia grande diferença entre a mortalidade masculina a a feminina. A partir de 1929, começa a haver uma diferença nitida entre as duas, sendo que, apenas em 193x, os coeficientes masculino e feminino são pràticamente iguais. A curva do gráfico 9 sugere que a diferença tende a se acentuar.

A explicação dêstes fatos é difícil e, provàvelmente, virios fatôress estão em jôgo. O fato de não haver uma diferença nitida no perrorlo anterior a 1929 talvez possa ser explicado unicamente por serem os numeros pequenos e, tais números, são inconsistentes. Quanto à diferença acentuada entro os dois sexos, a partir de 1929, pockemos lembrar a relação entre mortalidarle, morbidarle e letaliclade, jái menciornada na página 17 . E possível que a mortalidade maior nas mulheres seja devida à maior morbidade ou à maior letalidarde, ou, ainda, as duas coisas. 
WILSON, D. - MORTALIDADE POR DIABETES MELITO...

57

Tabela 11 - Mortalidade por diabetes melito no Município de São Paulo, segundo o sexo - 1900 a 1960.

\begin{tabular}{|c|c|c|c|c|}
\hline \multirow{2}{*}{ Anos } & \multicolumn{2}{|c|}{ Masculino } & \multicolumn{2}{|c|}{ Feminino } \\
\hline & obitos & Coeficiente ${ }^{*}$ & obitos & Coeficiente * \\
\hline 1900 & 2 & 1,66 & 1 & 0,90 \\
\hline 01 & 1 & 0,78 & 1 & 0,84 \\
\hline 02 & 4 & 2,91 & - & - \\
\hline 03 & 3 & 2,03 & 2 & 1,47 \\
\hline 04 & 2 & 1,29 & 4 & 2,76 \\
\hline 05 & 4 & 2,44 & - & - \\
\hline 06 & 1 & 0,58 & 1 & 0,62 \\
\hline 07 & 6 & 3,31 & 3 & 1,76 \\
\hline 08 & 2 & 1,05 & 4 & 2,24 \\
\hline 09 & 4 & 2,02 & 4 & 2,13 \\
\hline 1910 & 7 & 3,38 & 6 & 3,06 \\
\hline 11 & 4 & 1,86 & 10 & 4,89 \\
\hline 12 & 12 & 5,35 & 8 & 3,75 \\
\hline 13 & 6 & 2,58 & 6 & 2,70 \\
\hline 14 & 8 & 3,32 & 4 & 1,73 \\
\hline 15 & 7 & 2,80 & 4 & 1,67 \\
\hline 16 & 4 & 1,55 & 14 & 5,65 \\
\hline 17 & 19 & 7,13 & 6 & 2,34 \\
\hline 18 & 17 & 6,18 & 10 & 3,77 \\
\hline 19 & 12 & 4,23 & 9 & 3,28 \\
\hline 1920 & 12 & 4,11 & 10 & 3,53 \\
\hline 21 & 13 & 4,28 & 15 & 5,08 \\
\hline 22 & 18 & 5,69 & 22 & 7,14 \\
\hline 23 & 22 & 6,67 & 15 & 4,67 \\
\hline 24 & 16 & 4,66 & 9 & 2,69 \\
\hline 25 & 14 & 3,92 & 15 & 4,29 \\
\hline 26 & 22 & 5,91 & 20 & 5,49 \\
\hline 27 & 19 & 4,90 & 17 & 4,47 \\
\hline 28 & 31 & 7,68 & 24 & 6,05 \\
\hline 29 & 30 & 7,13 & 28 & 6,78 \\
\hline 1930 & 23 & 5,25 & 34 & 7,88 \\
\hline
\end{tabular}

(Continua) 


$$
\text { TABela } 11-(\text { Continuação })
$$

\begin{tabular}{|c|c|c|c|c|}
\hline \multirow{2}{*}{$A$ nos } & \multicolumn{2}{|c|}{ Masculino } & \multicolumn{2}{|c|}{ Feminino } \\
\hline & Obitos & Coeficiente * & Obitos & Coeficiente* \\
\hline 1931 & 18 & 3,95 & 45 & 10,00 \\
\hline 32 & 37 & 7,79 & 42 & 8,94 \\
\hline 33 & 37 & $\mathbf{7 , 4 8}$ & 37 & 7,55 \\
\hline 34 & 39 & $\mathbf{7 , 5 7}$ & 62 & 12,13 \\
\hline 35 & 49 & 9,14 & 71 & 13,32 \\
\hline 36 & 49 & 8,78 & 57 & 10,25 \\
\hline 37 & 48 & 8,25 & 78 & 13,45 \\
\hline 38 & 76 & 12,88 & 77 & 12,73 \\
\hline 39 & $\mathbf{5 7}$ & 9,04 & 83 & 13,15 \\
\hline 1940 & 54 & 8,22 & 89 & 13,52 \\
\hline 41 & 84 & 12,16 & 126 & 18,16 \\
\hline 42 & 80 & 11,02 & 124 & 16,96 \\
\hline 43 & 65 & 8,51 & 116 & 15,06 \\
\hline 44 & 82 & 10,21 & 124 & 15,27 \\
\hline 45 & 70 & 8,29 & 116 & 13,56 \\
\hline 46 & 78 & 8.78 & 119 & 13,20 \\
\hline 47 & 78 & 8,35 & 144 & 15.15 \\
\hline 48 & 85 & 8,66 & 161 & 16,08 \\
\hline 49 & 66 & 6,39 & 144 & 13,75 \\
\hline 1950 & 70 & 6,45 & 106 & 9,53 \\
\hline 51 & 91 & 7,98 & 160 & 13,65 \\
\hline 52 & 102 & 8,49 & 159 & 12,87 \\
\hline 53 & 117 & 9,26 & 237 & 18,21 \\
\hline 54 & 149 & 11,22 & 230 & 16,77 \\
\hline 55 & 158 & 10,91 & 258 & 17,21 \\
\hline 56 & 197 & 12,83 & 295 & 18,52 \\
\hline 57 & 185 & 11,37 & 333 & 19,69 \\
\hline 58 & 221 & 12,81 & 313 & 17,69 \\
\hline $\mathbf{5 9}$ & 240 & 13,12 & 399 & 20,89 \\
\hline 1960 & 254 & 13,10 & 421 & 20,75 \\
\hline
\end{tabular}

* Coeficientes específicos, segundo o sexo, por 100.000 habitantes.

Fonte: Departamento de Estatistica do Estado de São Paulo. 


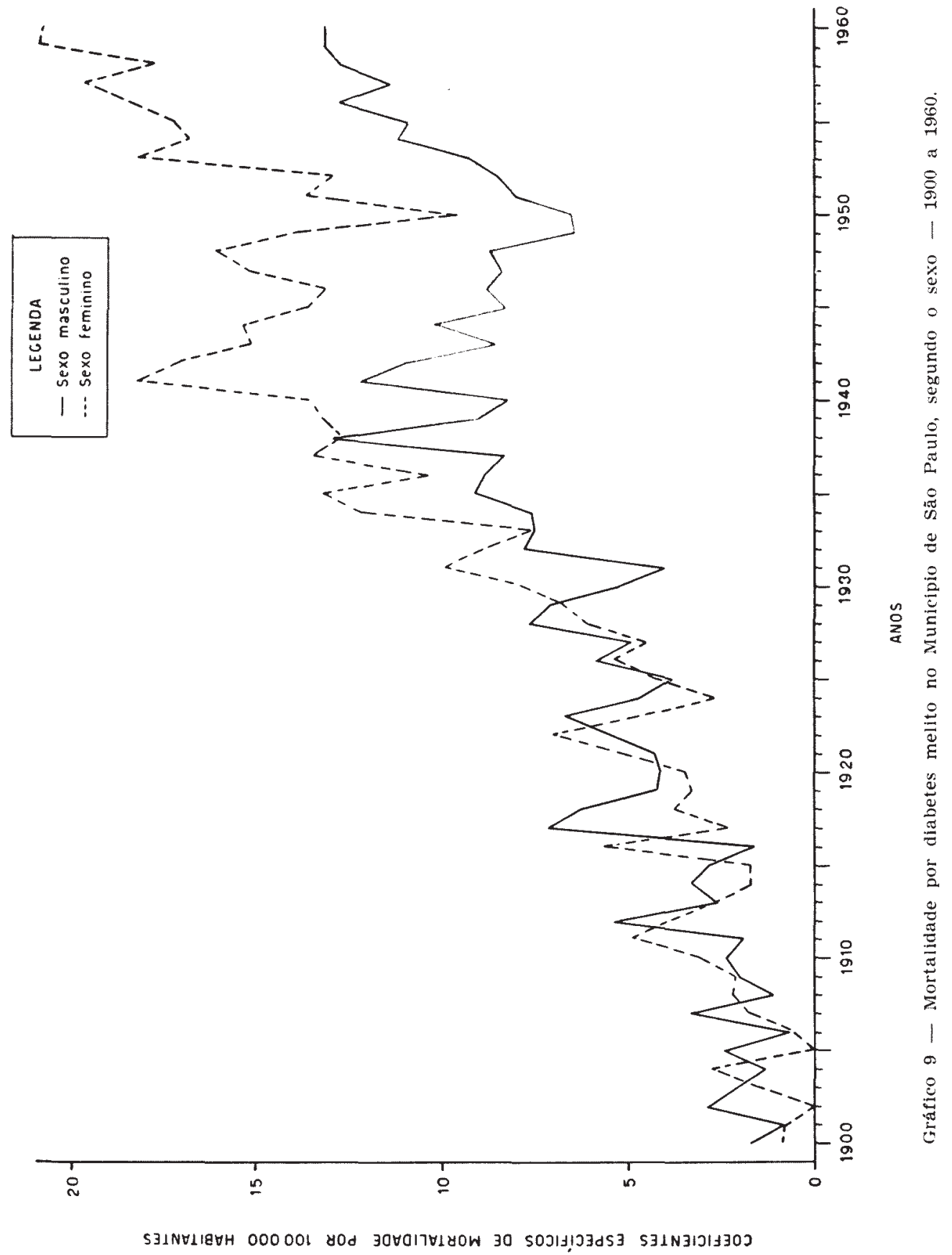


Futôres ligados à morbidade: 1) Distribuiçio designal nos dois seros - Seria possível, se o diabetes melito fôsse uma doença ligarla à hereditariedade "sex-linked", o que não parece ser verdarle".

2) Maior exposiçio aos futôres desencudeunte's - Pouco sabemos sôbre fatôres desencadeantes. Sabemos, entretanto, que a doença é mais freqüente em individuos que tem vida sedentária, e as muthres, no concenso geral, tém vida mais sedentária que os homens. Outro fator que tem sido apontado como desencarleante é a obesidarle: não temos idléia precisa se as mulheres são mais obesas que os homens. embora tenhamos a "impressão clínica" de que, realmente, sejam. I m terceiro fator, apontado como desencadeante, é o representado por determinadas perturbações hormonais que podem atingir o sèr humano, dentre as quais figura, como a mais importante, aquela que ocorre na gravidez.

Fatôres ligados à letalidade: 1) Processos infecerosos agudos Os processos infecciosos agudos, de um modo geral, agravam, transitòriamente que seja, o diabetes melito, podendo levar o doente ao coma. Os homens, em geral, estão mais expostos a tais processos, o que viria aumentar a mortalidare masculina.

2) Fulta de exercicio físico - Esste fator foi considerarlo como ligarlo à morbidarle, mas também o é à letalidade, pois um dos itens: do tratamento da doença é o exercício físico adequado. Já vimos cute a mulher, provàvelmente, sofre mais a influência dêste fator do cule o homem.

3) Graride: - Fiste fator está ligado, também, à letalidade pois, além de ser fator desencadeante, agrava o diabetes melito já instalado. Talvez seja este o fator mais importante.

Não podemos, apesar de tudo o que ficou dito, apontar um único fator que levasse a uma mortalidade maior no sexo feminino. Vários sãos os fatôres e muito temos, ainda, que pesquisar. Deremos acentuar que tôdas as possibilidades enumeradas são teóricas a não temos meios, com êstes dados, de demonstrar que o diabetes melito é mais freqüente na mulher, nem que seja mais letal para esta. A única maneira de que dispomos para obtermos provas de que êstes fatos são rerdadeiros é a pesquisa futura.

\section{RFSUMO}

O autor analisa os darlos de mortalidade por diabetes molito en um periodo de 61 anos. Conclui que a mortalidade proporcional está aumentando progresivamente $e$, nos últimos anos, acentuarlamente. I)e- 
momstra que os coeficientes de mortalidade também aumentam progressivamente, aumento êsse que não pode ser explicado, em sua totalidarle, pelo anmento da vida média.

Seus dados sugcrem que há um aumento da expectativa de vida do diabético, no período estudado, aumento êsse, provàvelmente, ligarlo a uma diminuição da letalidade dessa doença, mercê de melhor tratamento e molhora das condiçōes de vida em geral.

A distribuição da mortalidade segundo grupos etários muda com 1) correr do tempo, havendo um desvio em direção aos grupos mais iclosos, especialmente ao grupo 80 anos e mais.

Verifica que há uma diferença na mortalidade segundo os sexos nos últimos anos, a partir de 1929, enquanto que, nos primeiros trinta anos do período estudado, não se nota diferença apreciável. Invoca alguns fatôres que poderiam influir neste fenomeno, destacando a gradvidez.

\section{SU M M A R Y}

The author studies mortality data of diabetes mellitus over a period of 61 years. Ho finds that proportionate mortality rates increase progressiruly and in the last rears markedly; crude death rates for diabetes mellitus are also on the rise and that the increase can not be explained on the basis of increased life expectancy of the population alone.

His data suggest an increase in life expectancy for diabetics probably related to decrease in fatality.

Age distribution shows a shift to older age groups over the period under study:

The data show a sex difference in mortality by diabetes mellitus from 19:9 onward while before the mentioned year no such difference is apparent. He discusses a few lactors that could answer for the difference considering pregnancy probably the most important.

\section{$\triangle G R \triangle D E C I M F N T O$}

Somos gratos à Dra. Celeste A. de Souza Andrade, Diretor-Geral do Iepartamento de Estatística do Estado de São Paulo, e ao Sr. Walter Carvalho Teixeira, Diretor da Segunda Divisão do Departamento de Estatística do Estado de São Paulo, pela sua valiosa colaboração cedendo os dados de mortalidade utilizados neste trabalho. 


\section{REFERENCIAS}

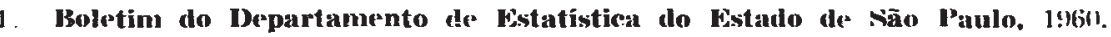

3. Hreslow, 1. Senescence, chronic disease and disability in adults. "I" Rosit' nau, M. J. Preventice Mediceiste and Public Heallh. Sth ed. ediled by K. F. Maxey. New York, Apple1on. 19.56. p. T44-7451.

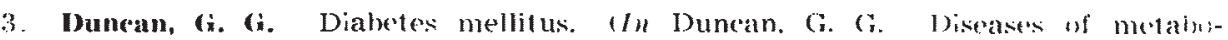

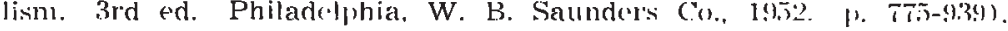

4. Forsham, P. H, \& Thorn, (i. W. The panceras. In Williams, R. H. Text book of endorerinology. 2nd ed. Philadelphia. W. 13. Salunders (No, lusit. 1). $4(1) 3-482.1$

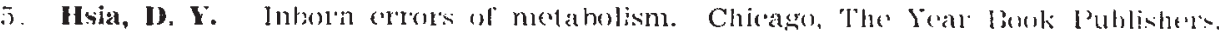
1459.

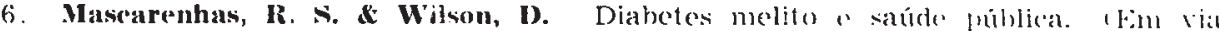

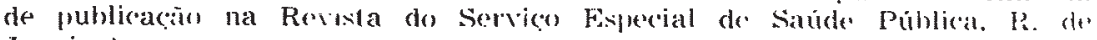
Jancirol.

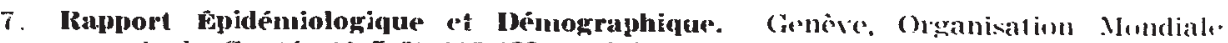
de la Santé. 12(5-6):116-133. mai jun. 19.j!

12(1):11, jan. 195ิ).

$13(1): 11$, jan. 1960

1(1. $14(1 ; 2): 21$, jan. fev: 1961.

11 Summary of Four-Year Keports on Health Conditions in the Ine-ricas. Wa-hington, Pan America: Sanitary Burcau, 1958. Is'ientific Publicalinn. n.: 40 1) $18-22$.

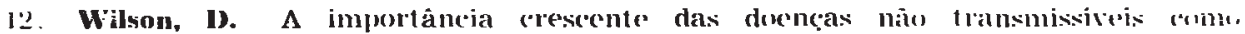

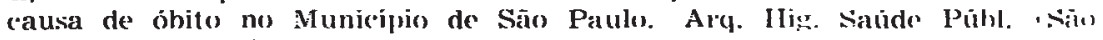
Paul()) श6(9) :305-312. de\%. 1961. 